\title{
EVALUATING THE ELECTRICITY SUPPLY IN TURKEY UNDER ECONOMIC GROWTH AND INCREASING ELECTRICITY DEMAND
}

\author{
Ahmet Yucekaya \\ Industrial Engineering Department, Faculty of Engineering and Natural Sciences, \\ Kadir Has University, Istanbul, Turkey \\ ahmety@khas.edu.tr
}

\begin{abstract}
The growing economy and residential consumption cause an increasing trend in the demand for electricity in Turkey. The country imports a quite ratio of its energy resources and heavily depend on the fossil fuels. On the other hand, the demand for the electricity that needs to be provided using resources that have minimum cost, sustainable supply and long term cycle is increasing parallel to the economic growth in the country. The long term investments on the renewable energy resources and hydroelectric plants affect the electricity supply. The country is planning to have a nuclear power plant in near future. Turkey stills provides the large part of its electricity from coal and natural gas. The natural gas based power generation is still expensive and that affect the power prices. In this research, the Turkish electricity market is analysed first, then the relationship between economic growth and electricity demand are analysed. The annual electricity demand and supply are also discussed.
\end{abstract}

Keywords: Electricity, deregulation, demand planning, Turkey, economic growth

\section{Introduction}

Electricity market activities, which are determined by Electricity Market Rule, are generation, transmission, distribution, wholesale trade, retail sale, retail trade service, commerce, importation and exportation. Transmission activities are performed by Turkish Electricity Transmission Incorporation. Moreover, Turkish Electricity Transmission Incorporation provides load distribution, frequency control, capacity addition, real time control of the system safety.

State directed regulations for the restructuring of electricity markets started in 2001 with the founding of the Energy Market Regulatory Authority (EMRA). Law 4628 aims for the deregulation of the electricity industry and the privatization of assets that are used to belong to 
the state. According to this law, the electricity industry is to be divided into smaller and manageable pieces in which generation, transmission and distribution are handled by different companies. The EMRA is the main authority that manages this process and oversees all related activities. The monopoly of state-owned resources is divided up into different companies such as EUAS (generation), TETAS (trading), TEDAS (distribution) and TEIAS (transmission). The main objective is to increase efficiency and provide a competitive market environment which can lower the cost of electricity and increase the reliability of power supply. The first step of the market design, which involves financial transactions in a deregulated electricity market, started on December 1, 2003. The power supplier and large number of consumers were encouraged to participate and invest in power markets at this time. The second step of the market design was defined as balance and conciliation, and it was launched on August 1, 2006. Participants carried out bidding and bilateral contracts in this step until the end of 2009. After this, participants started to submit monthly capacity and bids along with their schedules and a final market environment became active at the end of 2011.

On a typical day, the estimated day-ahead demand for each hour of the next day is announced by the ISO. The offers from the demand side (buyers) are also considered during this process. Each participant submits the amount of power they will supply, using bilateral contracts. These contracts are agreements between two parties that allow each participant to determine the power delivery conditions and price. The total amount of power that will be provided with the bilateral contracts is determined and deducted from the total estimated demand. Figure 3 shows the estimated demand and amount of power that was provided with bilateral contracts on July 17, 2012. The remaining amount should be supplied from competitive and reliable offers in the market. Hence, this is supportive of open competition [1].

The day-ahead process is divided into two different entities: the day-ahead planning and the day-ahead market. It is obligatory to submit the available capacity to the day-ahead planning so that the ISO can observe the status of resources. On the other hand, it is not obligatory to join to the day-ahead market and submit an offer.

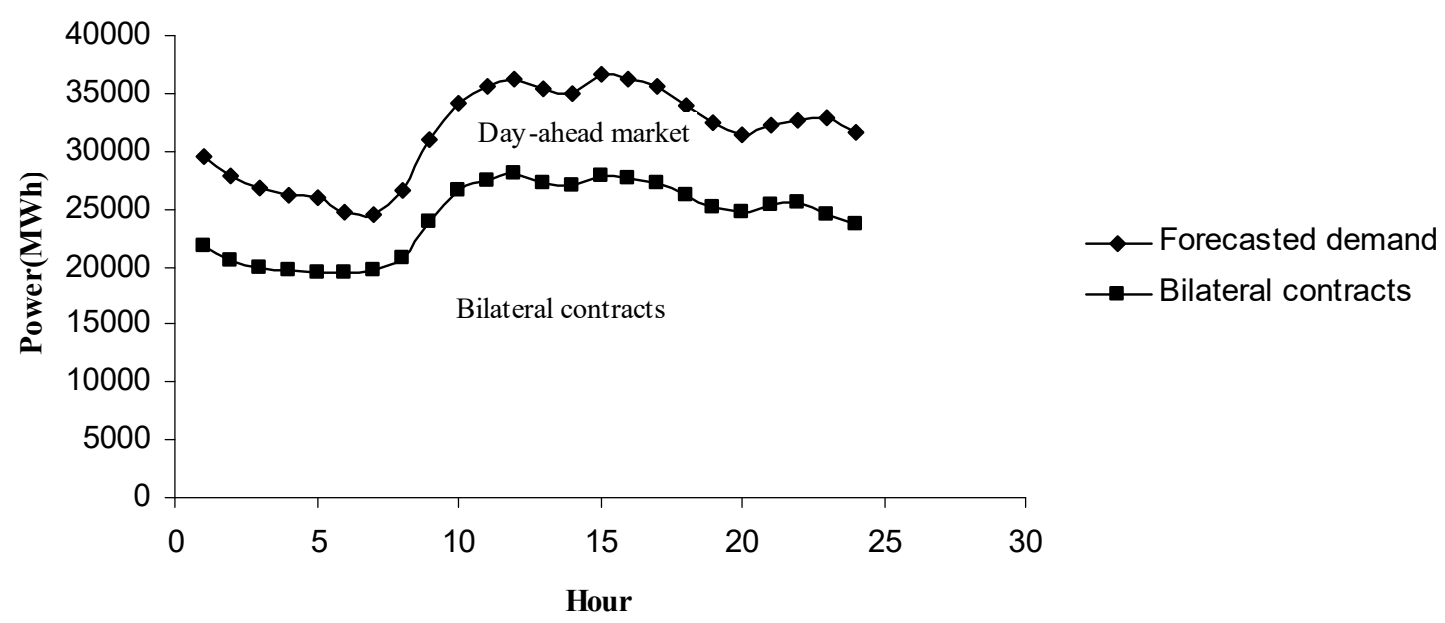

Figure 1. Estimated power demand and bilateral contracts, July 13, 2012

The market participants include the wholesale supplier, power plants, independent generation units and state resources that have the available capacity to submit sell bids to obtain power from day-ahead demand. In day-ahead planning, the main objective is to balance the supply and 
demand. On the other hand, in a day-ahead market, the objective of each participant is to maximize its portfolio. The planning allows the system operator to balance generation with buy requests submitted by market participants without considering the offer prices. In a day-ahead market, suppliers and buyers can balance their portfolio based on price levels. It is possible to submit hourly and block offers each day in both. Table 1 shows the order of activities in a dayahead market on a typical day.

Table 1. Activities in a day-ahead market

\begin{tabular}{|l|l|}
\hline Daily activities & Time \\
\hline Submit the bilateral contracts (before day-ahead) & $16: 00$ \\
\hline Submit the available capacity & $09: 30$ \\
\hline ISO determines the day-ahead demand and constraints & $11: 30$ \\
\hline Submit buy/sell bids & $11: 30$ \\
\hline Verify the bids & $12: 00$ \\
\hline ISO determines the hourly day-ahead prices and dispatched resources & $13: 00$ \\
\hline Submit the objections & $13: 30$ \\
\hline ISO announces the final results & $14: 00$ \\
\hline The operational day begins & $00: 00$ \\
\hline
\end{tabular}

The bilateral contracts should be submitted before the day-ahead planning begins. The contracts are submitted until 16:00 on the day before the day-ahead. Each participant is required to submit the available capacity and status of their resources by 9:30. The ISO estimates the day-ahead demand for each hour of the next day based on the temperature, submitted buy offers, bilateral contracts, and historical data. It is expected that there will be deviations from the estimated demand, as the demand and power consumption have stochastic and unpredictable features. The ISO also considers the transmission and outage constraints that affects dispatch decisions. Once the amount of power provided from the bilateral contracts is deducted, that amount of power must be supplied from the market for each hour. Each market participant submits buy and sell bids to the market at 11:30 and verifies the bids by 12:00 noon. The bids can be block bids or hourly bids that consist of power price and corresponding power quantity. ISO runs a security constrained cost minimization program to optimize the schedule of the resources. It is essential to order the sell offers from cheapest to highest and order the buy offers from highest to cheapest. Then the market clearing price for each hour is determined based on the offers and constraints, and then announced by the operator. Figure 2 shows the ratio of each option in Turkish power market. 


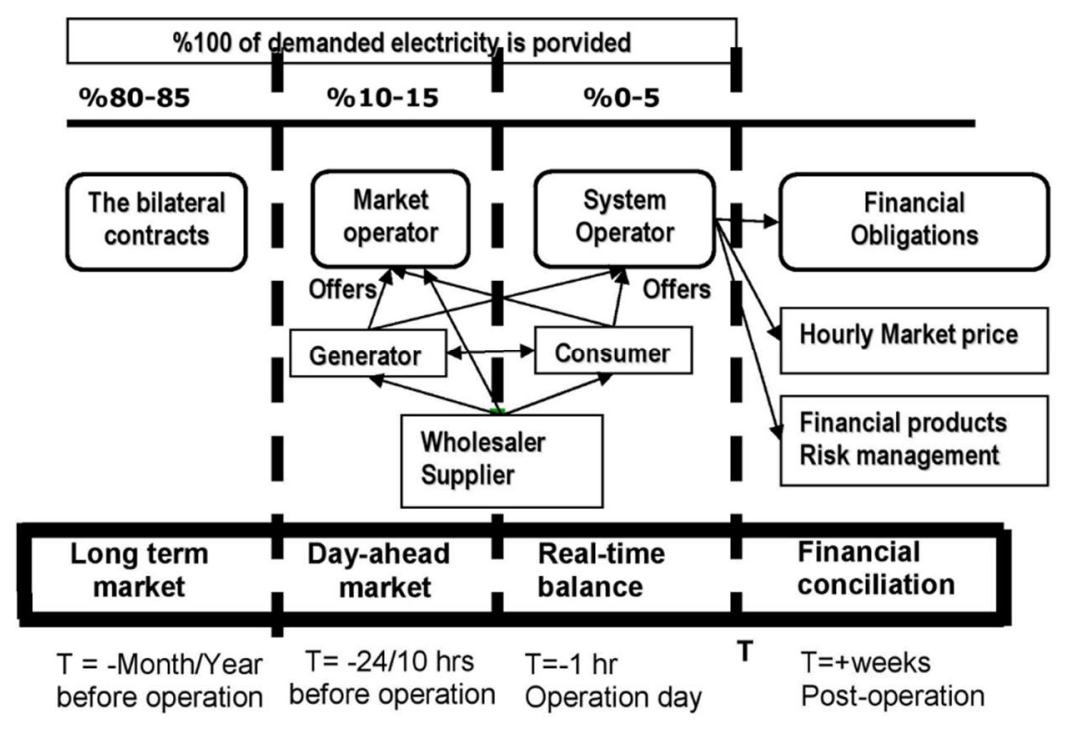

Figure 2. Turkish power market after deregulation

Each market participant is allowed to submit an objection within a given time limit. The final results are released after objections are resolved or the program is updated based on the requests. The program starts operation at midnight and runs for 24 hours. It is worth noting that usually $20-25 \%$ of power is supplied from the day-ahead market. Almost $75-80 \%$ of demand is still supplied using bilateral contracts. The idea of deregulation and its mechanism are not widely known or understood, as it is still under development and is relatively new. Power companies and large consumers still prefer to have bilateral contracts as the risk is low and it does not require dealing with a market mechanism. The contracts are usually prepared months or years ago before day-ahead activities. In this system, the day-ahead market and real-time balance should be considered together. The schedule for the day-ahead market is determined 10 hours before the actual day. On the other hand, the real time balance or real-time market is used to balance deviations from the estimated demand or planned schedule. $0-5 \%$ of electricity is handled in real time balance in which hourly decisions are effective. Generators, wholesale suppliers and consumers are allowed to submit bids to the day-ahead market or real-time balance. A supplier can submit in a day-ahead market or have reserves to be used in a real time balance. This reserve should also be offered to the real time market and hence the power that is not supplied through bilateral contracts and day-ahead market can be supplied in real time balance. The system operator determines the real time market price that will be used to calculate the payments for each resource in the real-time market. The system operator calculates the revenue or cost of each market participant based on the day-ahead market price, real time price and amount of power supplied from each resource. This process is called financial conciliation, in which each party is billed for the consumption or rewarded for the supply of power. The derivative market in Turkey began operations in 2005, and the operations for electricity options started in November 2011, and as such is relatively new. Financial products such as futures, forwards and options are generated and financial transactions are completed in a financial conciliation stage. This is usually weeks or months after the operation day [2].

On the other hand, it is not likely to meet the energy demand that is increasing as a result of the economic growth in Turkey with the current own resources. The researches that will allow resource planning, investment planning and optimum resource utilization are limited. In this 
research, the current situation in Turkey is analyzed first then the relationship between economic growth and electricity demand is analyzed.

\section{An evaluation for Turkish electricity market}

The demand for the electric power in Turkey is increasing that is also related to the economic growth. The country has observed an average of $4.52 \%$ annual economic growth between 20022016. The increasing industrial production, new investments and increasing population imposes an upper trend for electricity consumption. On the other hand, the electricity based appliances used for cooling in summer and heating in winter brings additional electricity consumption.

Turkey, having rich lignite resources, had preferred to build lignite or import coal based coal fired power plants. Natural gas power plants need a lower capital cost and they can be build up in a short time. The natural gas fuel cost is higher than coal and other electricity resources. Turkey is not a rich country in terms of water resources but current resources allow water resources to be the largest resource in terms of installed capacity. Table 2 shows the distributions of installed electricity capacities in Turkey between 2014-2016. As mentioned, the hydro resources have the largest share in the installed capacity with a share of $34.33 \%$ and the natural gas power plants have the second largest share with $32.77 \%$ and the coal fired power plants are third with a share of $21.83 \%$ in 2016.

Table 2. The installed capacities(MW) in Turkey based on the fuel type, 2014-2016

\begin{tabular}{|c|c|c|c|c|}
\hline \multirow{2}{*}{ Fuel Type } & Capacity(MW) & \multicolumn{3}{|c|}{ Ratio(\%) } \\
\cline { 2 - 5 } & 2016 & 2016 & 2015 & 2014 \\
\hline Coal (Lignite + Choking coal) & 10265.5 & 13.2 & 12.9 & 12.0 \\
\hline Coal (Import coal) & 7473.8 & 9.6 & 8.3 & 9.0 \\
\hline Natural gas & 25462.1 & 32.8 & 29.1 & 31.0 \\
\hline Hydro & 26678.0 & 34.3 & 35.4 & 34.0 \\
\hline Wind & 5747.7 & 7.4 & 6.2 & 5.0 \\
\hline Solar & 12.9 & 0.0 & 0.3 & 0.0 \\
\hline Geothermal & 820.9 & 1.1 & 0.9 & 0.0 \\
\hline Other(Oil+Multi-fuel) & 1242.1 & 1.6 & 7.1 & 9.0 \\
\hline Total & 77702.9 & 100.0 & 100.0 & 100.0 \\
\hline
\end{tabular}

The data shows that the investments for wind power, the natural gas power plants and coal plants are rising. There are increments for solar and geothermal as well however comparing with other resources they are still low. However not all the plants can fully operate in a year as expected. The reason for this might be a planned maintenance, unexpected outage, fuel supply problems, weather conditions etc. It is also possible that the cost of electricity becomes high due to high cost of fuel and hence the generation from this particular plant is not allowed. As a result, the distribution of the shares of the electricity generation plants based on the fuel types becomes different. Table 3 provides the distribution of the electricity generation based on the fuel types between 2014-2016 [1], [3], [4]. 
Table 3. The distribution of the electricity generation resources in Turkey, 2014-2016

\begin{tabular}{|l|r|r|r|r|}
\hline \multirow{2}{*}{ Fuel Type } & Generation (GWh) & \multicolumn{3}{c|}{ Ratio(\%) } \\
\cline { 2 - 5 } & \multicolumn{1}{|c|}{2016} & \multicolumn{1}{c|}{2016} & \multicolumn{1}{c|}{2015} & \multicolumn{1}{c|}{2014} \\
\hline Coal (Lignite + choking coal) & 44710.0 & 16.4 & 13.2 & 17.2 \\
\hline Coal (Import coal) & 47741.9 & 17.5 & 15.2 & 13.9 \\
\hline Natural gas & 87647.6 & 32.2 & 37.8 & 47.9 \\
\hline Hydro & 67303.1 & 24.7 & 25.8 & 16.1 \\
\hline Wind & 15501.4 & 5.7 & 4.5 & 3.4 \\
\hline Solar & 2.64 & 0.001 & 0 & 0 \\
\hline Geothermal & 4818.5 & 1.8 & 1.3 & 0.9 \\
\hline Other(Oil + multi-fuel) & 4838.9 & 1.8 & 2.2 & 0.6 \\
\hline Total & 272564.0 & 100 & 100 & 100 \\
\hline
\end{tabular}

It is obvious that the installed capacity does not necessarily mean that all of them will be used for electricity generation. Coal based generation has the largest share in electricity generation with $33.92 \%$, and natural gas has the second largest share with $32.16 \%$ in 2016 . Hydro resources on the other hand depend on the rainfall and water inflows have $24.69 \%$ share in electricity generation in the same period. The amount of electricity that is supplied from natural gas power plants decreased between 2014-2016 that is usually replaced by the hydro based power generation. The coal based power generation follows a stable pattern whereas the wind power rises.

Figure 3 shows the distribution of primary energy sources in Turkey [1]. 26\% of the primary energy source is electricity which includes industrial use and residential use. $52 \%$ of the primary energy source is natural gas which also includes industrial and residential use.

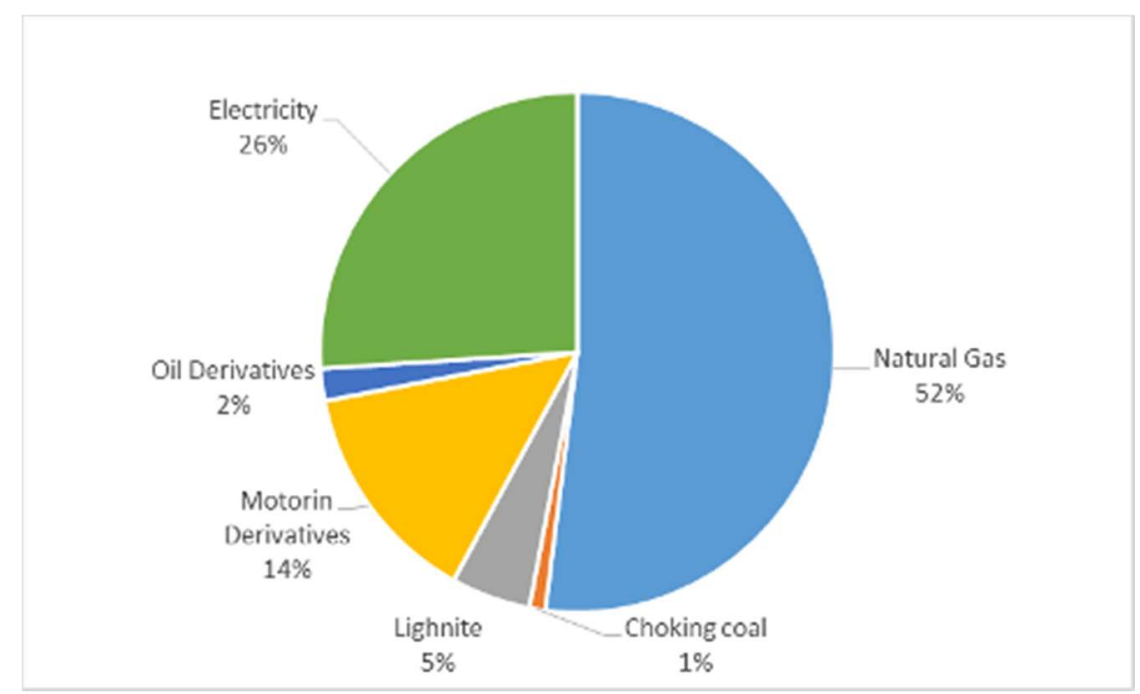

Figure 3. Primary energy sources in Turkish energy market

Total electricity demand in Turkey turned out as 277522 GWh in 2016. Then average hourly demand can be estimated as $31680 \mathrm{Mwh}$. The electricity demand decreases in nights and peaks in hot summer days and cold winter days. However, economic growth effects the growth in electricity generation very much. Figure 4 shows the change in economic growth for Turkey. Figure includes both cumulative and annual growth rates [4], [5], [6]. 


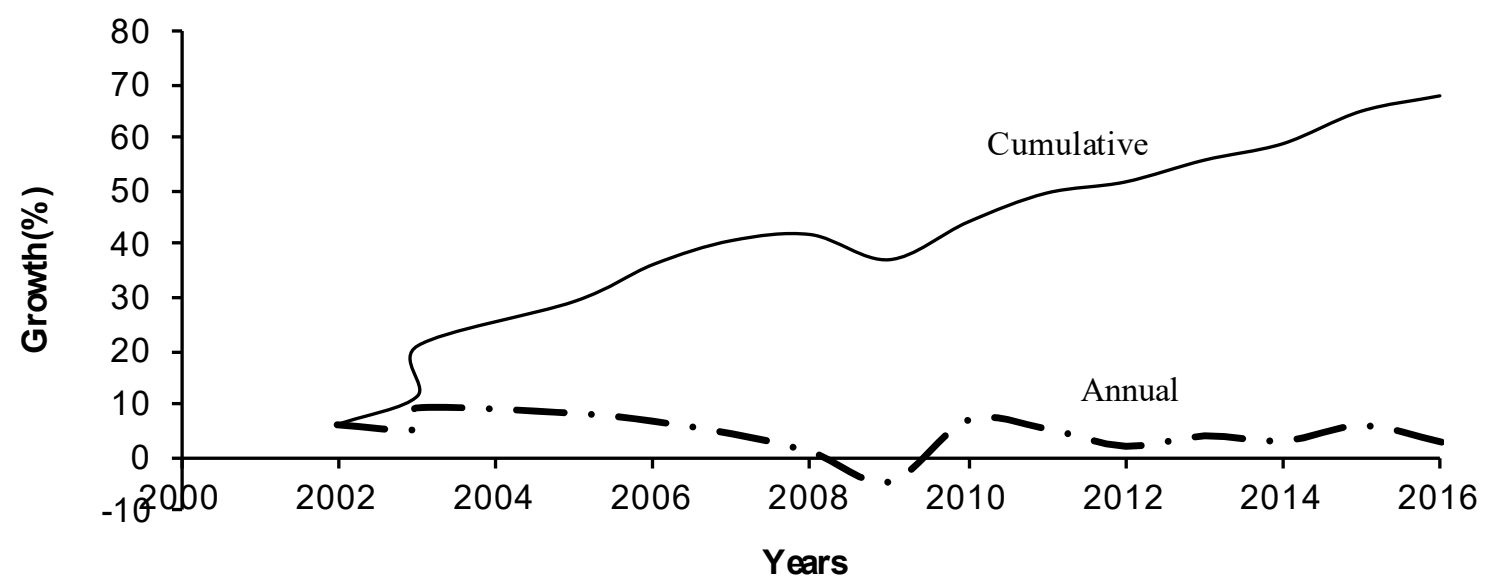

Figure 4. Annual economic growth by years in Turkey

A large share of electricity is being used by the industry. The utilization of the machines and equipments in industry depends on the economic growth. Figure 5 presents the relationship between annual economic growth and annual electricity demand in Turkey. The correlation coefficient for the 14 years period is 0.70 which is quite high. Note that the data for the electricity generation includes both residential and industrial electricity demand. If we had just the industrial electricity demand, the correlation coefficient might be higher.

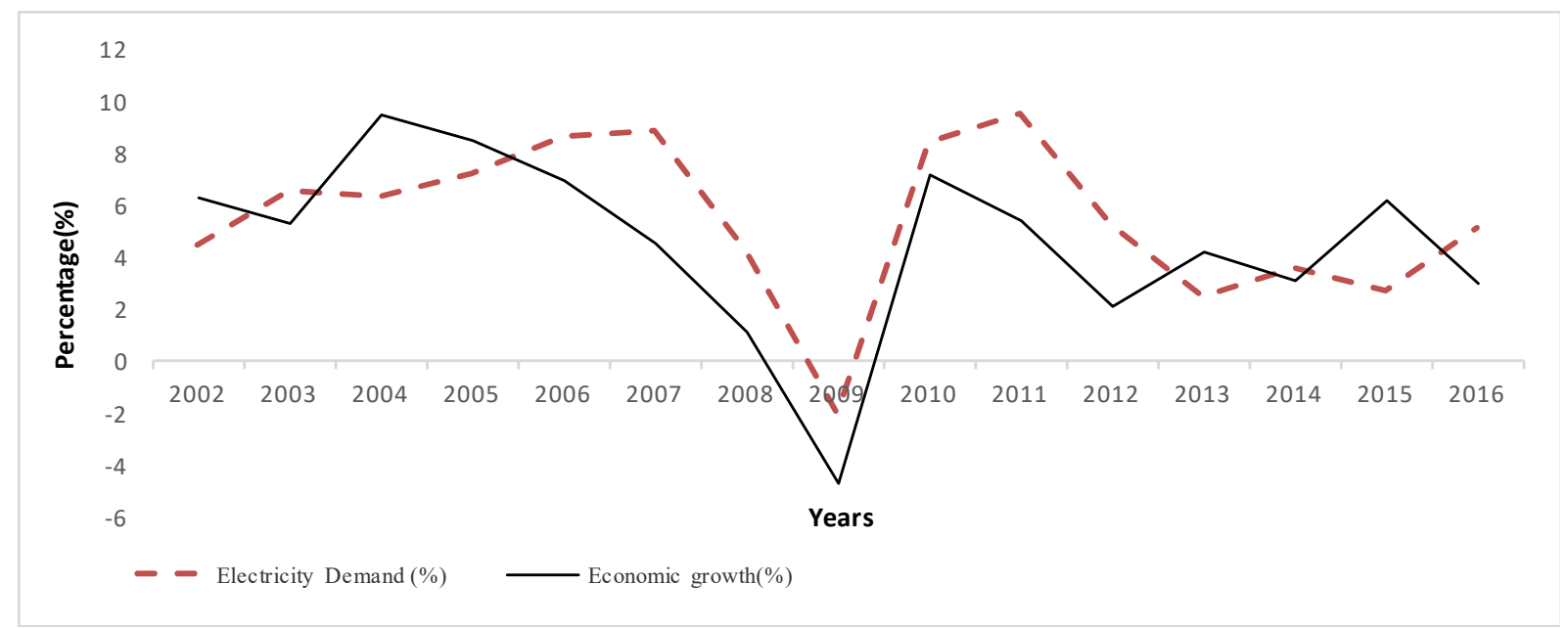

Figure 5. The relationship between annual economic growth and electricity demand

The strong relationship between annual economic growth and annual electricity demand in Turkey can be expected for the cumulative economic growth and electricity demand as well. Figure 6 presents cumulative economic growth and annual electricity demand in Turkey. The correlation coefficient for the 14 years period is 0.985 which shows that there is strong relationship between two. The total economic growth reaches $80,97 \%$ whereas the total electricity demand reaches $67.9 \%$ in 2002-2016. 


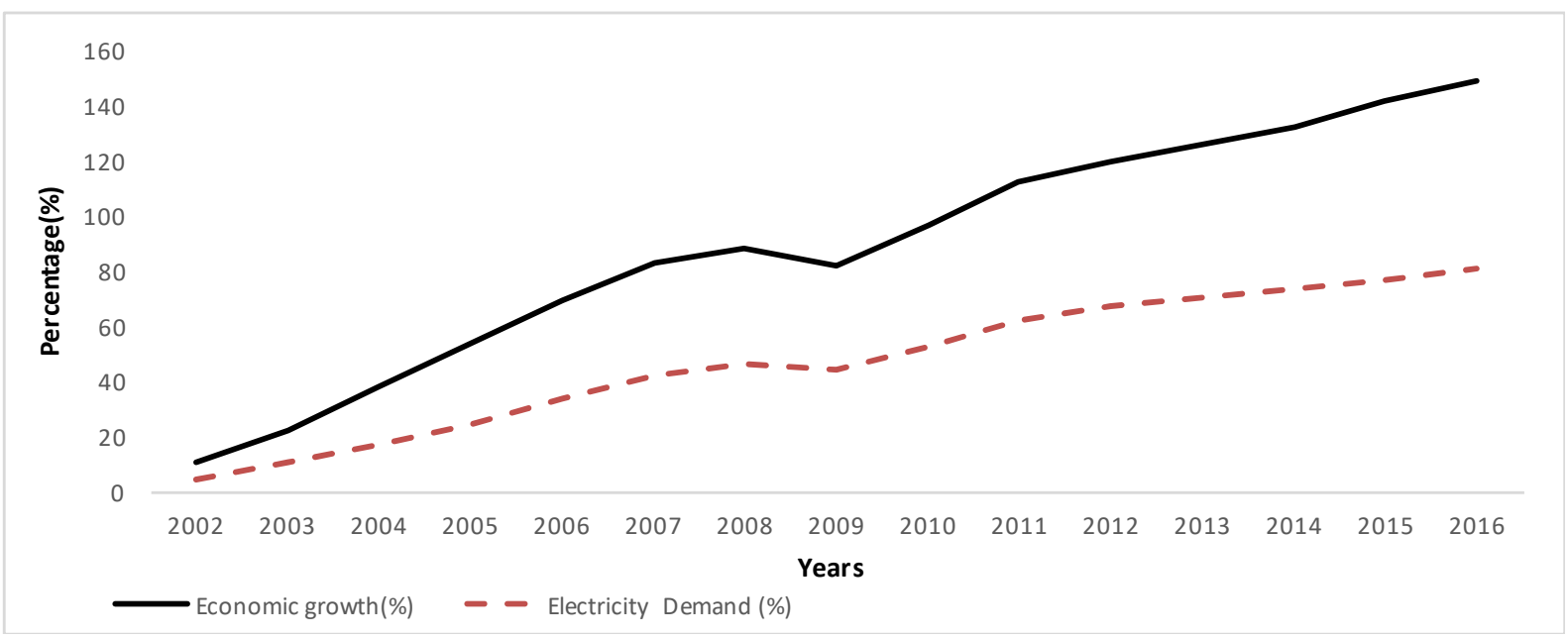

Figure 6. The relationship between cumulative economic growth and electricity demand

Electricity consumption and demand between 2012-2016 period showed an almost linear increase and reached to the limit of generation resources. Figure 7 shows the change in electricity demand in 1991-2016. The drought between 2006-2008 forced hydro electric power resources to stop operating and supply and demand reached to almost breakeven. There was also some electricity imports from neighboring countries. The figure shows the total consumption and the percentage change in the consumption. Notice that we see obvious decreases in 2000 and 2008 due to economic crises.

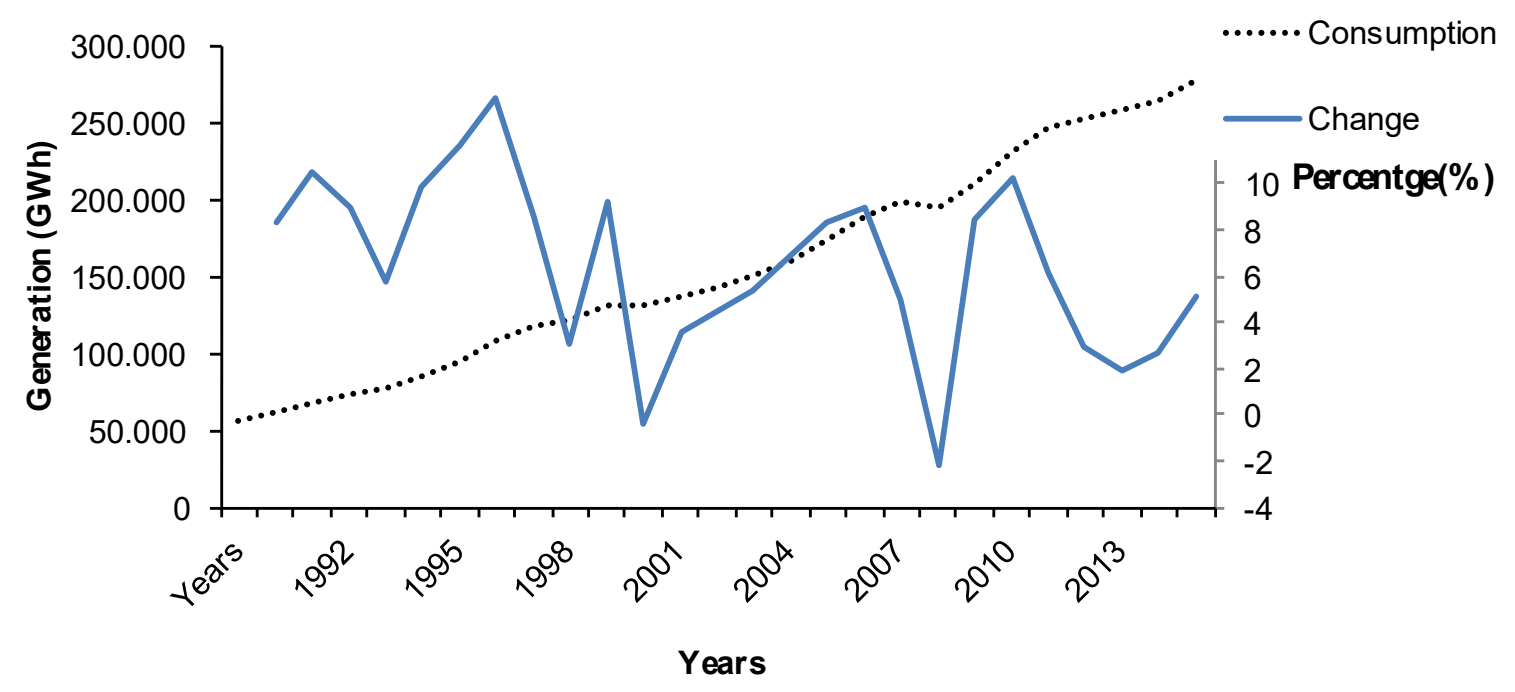

Figure 7. The change in electricity consumption

\section{Conclusion}

Energy and natural resources became the most important products in the world. Energy is the major reason for wars and fundamental for a competitive economy. Turkey, when compared to developed countries, uses old power generation technologies and has very scarce energy resources. In this paper, a review on the electricity market has been presented first. Than the 
relationship between economic growth and electricity generation is analyzed using annual and cumulative data. We have found out strong correlation between two. It is estimated that the economic growth will continue in Turkey and hence electricity demand will do so. The rise in the electricity demand can be estimated based on the expected rate of economic growth according to presented research.

There are strong commitments for renewable energy sources such as wind and solar in developed countries. Turkey should focus more on renewables. Another step might be to renovate and upgrade coal fired power plants as the technology is considered old. In the demand management side, community should be trained for demand minimization and waste elimination so as to optimize resource utilization. The country plans to build nuclear power plants which are expected to operate in next decade. This step might increase the reliable capacity and fossil fuel based generation might be eliminated. This step is important as the coal resources in Turkey have lower heat values with higher emission content. The environmental impact might be minimized. The incentives for renewables such as solar and wind are pretty useful for attracting investments both at national level and international level. The incentives should be reevaluated and new investments should always be supported.

\section{References}

[1] EPDK, Enerji Piyasasi Duzenleme Kurumu, www.epdk.gov.tr, 2017.

[2] Yukseltan, E., Yucekaya, A., Bilge, A., "Forecasting electricity demand for Turkey: Modeling periodic variations and demand segregation", Applied Energy, Vol. 193(2017), pp.287-296.

[3] EIA, Energy Information Administration, http://www.eia.gov/, 2017.

[4] IEA, International Energy Agency, http://www.iea.org/country/index.asp, 2017.

[5] EEC, Energy Infrastructure, European Energy Commission, http://ec.europa.eu/energy /publications/index en.htm, 2017.

[6] Country Profiles, World Bank, http://data.worldbank.org/, 2017 